\title{
Measurement of the True Incidence of Secondary Haemorrhage Post Tonsillectomy
}

\author{
Luke Holmes and Vik Veer* \\ Department of Ear Nose and Throat Surgery, James Cook University Hospital, Middlesbrough, UK \\ *Corresponding author: Vik Veer, Department of ear nose and throat surgery, James cook university hospital, Middlesbrough, UK
}

Submission: June 21, 2018; Published: September 04, 2018

\begin{abstract}
Aim: To determine the 'true' secondary haemorrhage rate post-tonsillectomy.

Methods: A telephone survey was conducted of 127 consecutive patients who had a tonsillectomy at the Freeman Hospital over a two-month period.

Results: 99 patients were contactable. There were 38 post-tonsillectomy bleeds, 23 of which were minor and 15 significant. 23 bleeds went unreported and four of these were significant. 11 percent of bleeds post-cold steel tonsillectomy were significant, compared to 28 percent of bleeds post-diathermy dissection.

Conclusion: There is a high incidence of unreported bleeding (61 percent of those that bled) and a third of adults who suffered a significant bleed did not report it. Diathermy had a significantly higher proportion of significant bleeds compared to cold steel. It is recommended if secondary haemorrhage rates are reported in the literature then small studies should contact patients for 'true' secondary bleed rates while large studies should use return to theatre and need for transfusion rates.
\end{abstract}

\section{Introduction}

Tonsillectomy remains one of the most frequently performed operations within the NHS and Hospital Episode Statistics report over 50,000 were performed in 2011-2012 [1]. It is a procedure routinely performed for recurrent tonsillitis, obstructive sleep apnoea and recurrent peritonsillar abscess $[2,3]$. It has relatively few complications, but one of the most serious is post-tonsillectomy haemorrhage.

Post-tonsillectomy haemorrhage is termed primary if it occurs within the first 24 hours and secondary after this period elapses. Widely differing rates of secondary haemorrhage have been reported in the literature, ranging from forty percent to as low as one percent [4-10]. These differences are largely due to different distinctions used to qualify a bleed, the length of initial hospital stay, type of follow-up and variable reporting by patients. The rate of secondary haemorrhage has also been linked to operational technique. The National Prospective Tonsillectomy Audit in 2005 found that 'hot' surgical techniques for both dissection and haemostasis had a haemorrhage risk three times that of cold steel tonsillectomy without the use of a hot technique [11]. However, several studies show differing bleed rates for similar techniques $[12,13]$ and many surgeons continue to use 'hot' techniques as they have found that their own rates are comparable to the national 'cold steel' average.

The National Prospective Tonsillectomy Audit stated the readmission rate for secondary haemorrhage was approximately four percent and return to theatre rate was one percent [11]. This study sought to investigate the 'true' secondary haemorrhage rate by contacting each patient after their operation to ascertain if they had experienced a bleed.

\section{Patients and Methods}

127 patients who had a tonsillectomy performed at the Freeman Hospital, Newcastle, were contacted via telephone one month after their operations. The sample consisted of 81 adults and 46 children (aged below 16). Adults were questioned directly and in the case of children, their parents interviewed.

The simple questionnaire consisted of 6 inquiries:

A. Did you suffer any sort of postoperative bleed?

B. If yes, how long after the operation?

C. Did you bleed continuously for less than one minute or longer than one minute?

D. Did you bleed at any other time?

E. Did you contact a medical professional about it? 
F. If yes, how were you managed?

A bleed of less than one minute was classified as minor, and a bleed greater than one minute as significant. This point was clearly qualified with the patient, as blood actively running for greater than a minute. Multiple presentations were only counted once. Details about each patient's tonsillectomy operation were also collected from the medical notes. In a few cases the operative procedure wasn't fully detailed and the individual surgeon's usual practice was assumed.

\section{Results}

Data was obtained from 99 of the 127 patients who had tonsillectomies in the selected period, which represented 78 percent of the sample. Of these 99,38 (38 percent) reported a posttonsillectomy bleed (Figure 1). Of the 38 post-tonsillectomy bleeds, 23 (61 percent) went unreported. In total there were 23 minor bleeds and 15 significant bleeds (Figure 2).

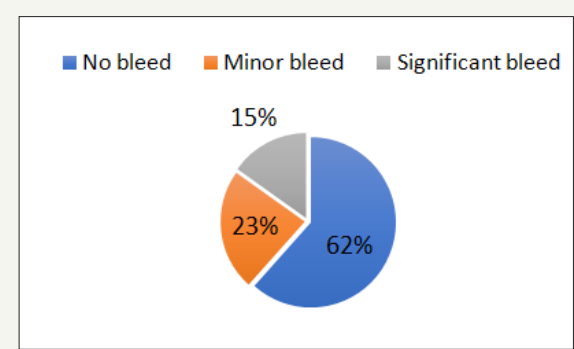

Figure 1: Post-tonsillectomy bleed rates in 99 patients interviewed.

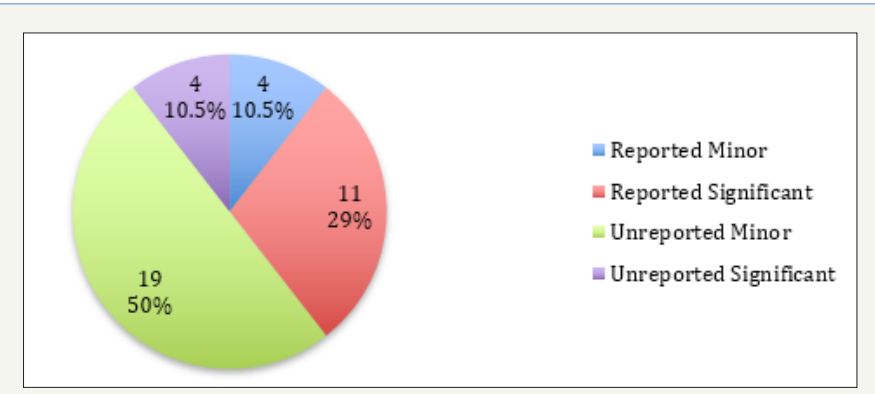

Figure 2: Categorisation of 38 post-tonsillectomy bleeds.

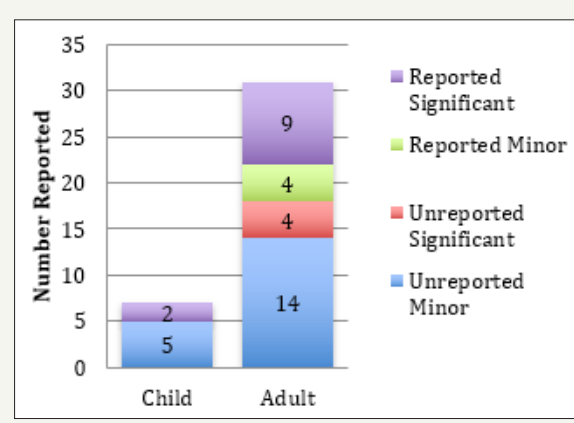

Figure 3: Comparison of bleed types in children and adults.

Of the 38 people who experienced bleeding, only 15 reported the incident to a health professional, the vast majority of which visited A\&E (14 of the 15 reported). Of the 23 people who didn't report their bleeding, four individuals suffered a significant bleed, the remaining 19 described minor bleeding (Figure 2). Notably, of the four significant unreported bleeds, two heralded a larger episode of bleeding requiring hospital admission. Of the 15 reported bleeds, 11 were significant while four were minor (Figure 3). Of the 11 significant bleeds reported, seven of these were sent home by A\&E without consulting ENT as the bleeding had resolved. There were a total of six readmissions equating to a 4.7 percent readmission rate and a 0.8 percent return to theatre rate (accounted for by one individual).

There were seven children in whom a bleed occurred, five of these were significant and reported, while two minor bleeds went unreported. 31 adults bled and 18 of these were minor, of which 14 went unreported (Figure 3). Of the 13 significant bleeds in adults, four went unreported (31 percent). The majority of minor bleeds occurred in the first 24-72 hours while significant bleeds tended to occur between days three and eight (Figure 4).

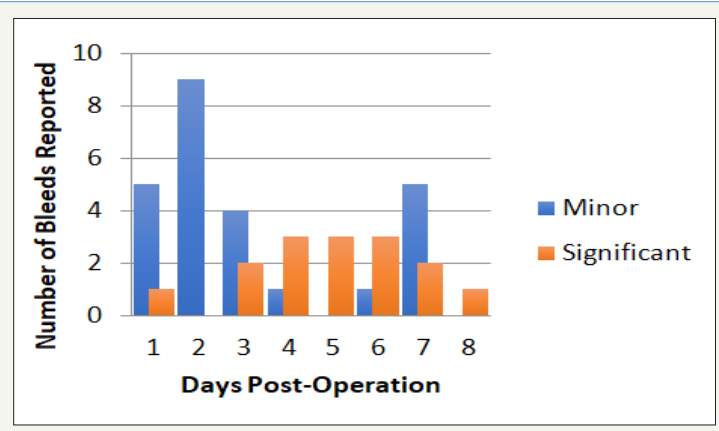

Figure 4: Timing of reported bleeds.

Of the 99 procedures performed on interviewees, there were 74 cold steel operations and 25 used a diathermy technique see Table 1. Pearson's Chi-squared analysis revealed no significant difference when comparing the overall bleed rates for these two techniques, 37 percent and 40 percent for cold steel and diathermy respectively $(p=0.754)$. However, looking at the severity of the bleed experienced, diathermy demonstrated a significantly higher rate of significant bleeds, 28 percent versus 11 percent $(\mathrm{p}=0.038)$.

Table 1: Comparison of "hot" versus cold steel technique bleed rates.

\begin{tabular}{|c|c|c|c|c|c|}
\hline Method & No. Ops & $\begin{array}{c}\text { No. } \\
\text { Bleeds }\end{array}$ & $\begin{array}{c}\text { \% } \\
\text { Bleeds }\end{array}$ & $\begin{array}{c}\text { No. Sig. } \\
\text { Bleeds }\end{array}$ & $\begin{array}{c}\text { \% Sig. } \\
\text { Bleeds }\end{array}$ \\
\hline Cold Steel & 74 & 27 & $37 \%$ & 8 & $11 \%$ \\
\hline Diathermy & 25 & 10 & $40 \%$ & 7 & $28 \%$ \\
\hline
\end{tabular}

\section{Discussion}

This study has highlighted a high incidence of some degree of post-tonsillectomy bleeding (38 percent of the sample) and that much of this goes unreported (62 percent of those that experienced a bleed). Significant bleeds tended to occur between days 3-8 as opposed to minor bleeds that were often in the first 24-72 hours. Significant bleeds were always reported in children but four adults with a significant bleed went unreported. This has important ramifications, especially considering two of these individuals 
went on to bleed again more seriously, requiring admission to hospital. Of interest was the fact that seven of the eleven significant bleeds presenting to an A\&E department, were sent home without consultation with the ENT specialist on-call, as they weren't bleeding on arrival. This could be potentially dangerous practice, as these bleeds can be the precursor to a larger event as noted previously.

Regarding unreported bleeds it was unsurprising that most of these were minor in nature. Typically, fresh blood in the sputum, blood spotting on the pillow or less than a teaspoon in volume. This is often viewed as insignificant and so not bought to the attention of a health professional. There were also other factors that influenced if a patient reported their bleed or not, namely time of day, how busy they were, transportation and distance to a healthcare center.

Although cold steel and diathermy, when compared in terms of overall bleed rates, were not significantly different (37 percent versus 40 percent respectively, $p=0.754$ ), use of diathermy correlated with a significantly higher rate of significant bleeds (28 percent versus 11 percent, $\mathrm{p}=0.038$ ). This indicates that although the overall risk of bleeding is similar, it is more likely to be a significant event when a 'hot' technique is used, so more likely to lead to presentation to a health professional and admission to hospital for observation.

The factors mentioned above are likely the reason there is so much variability in the literature regarding reported differences in secondary haemorrhage rates post-tonsillectomy. These variables directly affect re-admission rates, which make this statistic an inaccurate measure of the rate of secondary haemorrhage post tonsillectomy, a figure often quoted in the literature. Readmission rates are further complicated by other situational and local factors such as if an ENT doctor is present on site, if A\&E have specific criteria to provoke referral to ENT and if a patient would require transfer to another hospital for further evaluation. If secondary haemorrhage rates are going to be used in the literature as a gauge to measure tonsillectomy outcomes, we propose that small studies contact patients for 'true secondary bleed rates' while large studies should use return to theatre and need for transfusion rates, which are more reliable statistics than the readmission rate.

The information revealed by this study aids practice as it gives an accurate picture of the 'true' bleed rate once patients are discharged from hospital. Not only is this important for understanding how this relates to the actual readmission and return to theatre rates, but also so that patients can be accurately informed as to what to expect during the post-operative course. Evidence that significant bleeds are still being unreported in the community also highlights the fact that it should be stressed strongly to patients that a herald bleed can be an important early warning sign of another potentially serious haemorrhage.

\section{Acknowledgement}

Aaron Koshy, medical student who presented a poster at the North of England society meeting on the $8^{\text {th }}$ March 2013.

\section{References}

1. https://digital.nhs.uk/

2. Darrow DH, Siemens C (2002) Indications for tonsillectomy and adenoidectomy. The Laryngoscope 112 (8 Pt 2 Suppl 100): 6-10.

3. Rosenfeld RM, Green RP (1990) Tonsillectomy and adenoidectomy: changing trends. The Annals of otology, rhinology, and laryngology 99(3 Pt 1): 187-191.

4. Blomgren K, Qvarnberg YH, Valtonen HJ (2001) A prospective study on pros and cons of electrodissection tonsillectomy. The Laryngoscope 111(3): 478-482.

5. Windfuhr J, Seehafer M (2001) Classification of haemorrhage following tonsillectomy. The Journal of laryngology and otology 115(6): 457-461.

6. Benson MR, Maw AR (1993) Assessment of sequelae at home following enotonsillectomy. A basis for day-case management? Clinical otolaryngology and allied sciences 18(4): 282-284.

7. Ghufoor K, Frosh A, Sandhu G, Hanif J (2000) Post-tonsillectomy patient care in the community. International journal of clinical practice 54(7): 420-423.

8. Kuo M, Hegarty D, Johnson A, Stevenson S (1995) Early posttonsillectomy morbidity following hospital discharge: do patients and GPs know what to expect? Health trends 27(3): 98-100.

9. Lee WC, Sharp JF (1996) Complications of paediatric tonsillectomy postdischarge. The Journal of laryngology and otology 110(2): 136-140.

10. Raut V, Bhat N, Kinsella J, Toner JG, Sinnathuray AR, et al. (2001) Bipolar scissors versus cold dissection tonsillectomy: a prospective, randomized, multi-unit study. The Laryngoscope 111(12): 2178-2182.

11.(2005) Clinical Effectiveness Unit RCoSoE. National Prospective Tonsillectomy Audit. Final report of an audit carried out in England and Northern Ireland between July 2003 and September 2004. pp. 1-40.

12. Walner DL, Miller SP, Villines D, Bussell GS (2012) Coblation tonsillectomy in children: incidence of bleeding. The Laryngoscope 122(10): 2330-2336

13. Windfuhr JP, Deck JC, Remmert S (2005) Hemorrhage following coblation tonsillectomy. The Annals of otology, rhinology, and laryngology 114(10): 749-756.
Creative Commons Attribution 4.0 International License

For possible submissions Click Here

\section{Submit Article}

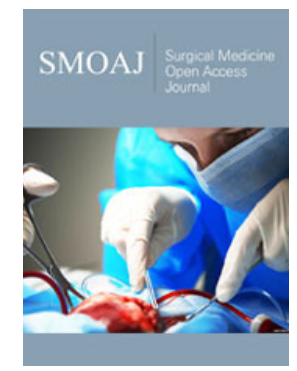

\section{Surgical Medicine Open Access Journal}

\section{Benefits of Publishing with us}

- High-level peer review and editorial services

- Freely accessible online immediately upon publication

- Authors retain the copyright to their work

- Licensing it under a Creative Commons license

- Visibility through different online platforms 